Review

\title{
Cyclodextrins in Asymmetric and Stereospecific Synthesis
}

\author{
Fliur Macaev ${ }^{\dagger}, *$ and Veaceslav Boldescu ${ }^{\dagger}$ \\ Institute of Chemistry of the Academy of Sciences of Moldova 3, Academiei str., Chisinau MD2028, \\ Moldova; E-Mail: veaceslav.boldescu@gmail.com \\ $\dagger$ These authors contributed equally to this work. \\ * Author to whom correspondence should be addressed; E-Mail: flmacaev@cc.acad.md; \\ Tel.: +373-22-739-754; Fax: +373-22-739-954.
}

Academic Editor: Svetlana Tsogoeva

Received: 1 July 2015 / Accepted: 16 September 2015 / Published: 24 September 2015

\begin{abstract}
Since their discovery, cyclodextrins have widely been used as green and easily available alternatives to promoters or catalysts of different chemical reactions in water. This review covers the research and application of cyclodextrins and their derivatives in asymmetric and stereospecific syntheses, with their division into three main groups: (1) cyclodextrins promoting asymmetric and stereospecific catalysis in water; (2) cyclodextrins' complexes with transition metals as asymmetric and stereospecific catalysts; and (3) cyclodextrins' non-metallic derivatives as asymmetric and stereospecific catalysts. The scope of this review is to systematize existing information on the contribution of cyclodextrins to asymmetric and stereospecific synthesis and, thus, to facilitate further development in this direction.
\end{abstract}

Keywords: cyclodextrin; asymmetric synthesis; enantioselective organocatalysis; transition metal complexes; asymmetric catalysis; catalytic systems

\section{Introduction}

Cyclodextrins (CDs) have long been known to be good contributors to the development of catalytic processes. They have been used for mass-transfer catalytic reactions and for the production of new catalysts mimicking enzymatic activity. CDs are a class of naturally-occurring oligosaccharides constituted of six $(\alpha-C D)$, seven $(\beta-C D)$ or eight $(\gamma-C D)$ D-glucopyranose units. Each CD molecule represents a torus in which the inner surface possesses somewhat hydrophobic properties and the outer 
surface is hydrophilic. The wider radius of the torus is surrounded by the secondary hydroxyl groups, while the narrower one contains all of the primary ones.

Hapiot et al. [1] have proposed the following classification for catalytic applications of cyclodextrins:

(1) to significantly increase the rate and selectivity of reactions catalyzed by water-soluble organometallic complexes;

(2) to design new water-soluble ligands for aqueous organometallic catalysis;

(3) to stabilize catalytically-active noble metal nanoparticles in water;

(4) to facilitate reactions catalyzed by supported metals or metallic powder in water.

Cyclodextrins have long been used in organic synthesis as promoters or catalysts of different reactions [2]. They are very attractive as components of artificial enzymatic systems [3] and can also be used as stabilizers for the nanodimensional metallic catalysts, thus enhancing their catalytic activity [4]. A comprehensive collection of recent breakthroughs in aqueous cyclodextrin-assisted supramolecular catalysis can be found in the review by Hapiot et al. [5].

Cyclodextrins have also been successfully used as powerful resolving agents for racemic mixtures [6], as well as separating agents in gas chromatographic chiral resolution of enantiomers [7-9].

It is a well-known fact that the formation of an inclusion complex between the $\beta$-CD unit of a catalytic system and a substrate leads to an increase of the local concentration of the latter and immobilizes it near the catalytically-active center. As a result, acceleration in the reaction rate, higher substrate selectivity, enantioselectivity and regioselectivity can often be achieved.

In this review, we present an analysis of the main publications on cyclodextrins' application in enantioselective and stereospecific syntheses.

We propose the following division of the topics according to the structure and functionality of the cyclodextrin-based catalysts:

1) cyclodextrins' complexes with transition metals as asymmetric and stereospecific catalysts;

2) cyclodextrins' non-metallic derivatives as asymmetric and stereospecific catalysts;

3) cyclodextrins promoting asymmetric and stereospecific catalysis in water.

Cyclodextrins from the first two groups, as a part of the metal-containing or non-metallic catalytic systems, contribute to the catalysis of the asymmetric or stereospecific synthetic processes via specific inclusion of the molecules. Cyclodextrins from the third group play the role of "reactor" or "chiral container" in which or by which the asymmetric or stereospecific synthesis is facilitated. We hope that systematization and analysis of the recent developments in the application of cyclodextrins in asymmetric and stereospecific synthesis presented in this review will further facilitate the development of this field.

\section{Results and Discussion}

\subsection{Cyclodextrins' Complexes with Transition Metals as Asymmetric and Stereospecific Catalysts}

Catalytic properties of the cyclodextrins can be complemented with chemically-reactive subunits, either by attaching functional groups, such as acid-base catalysts, or by linking cyclodextrins to metal complexes. As a result, in the majority of cases, an outstanding reactivity and a very high degree of 
stereoselectivity can be observed. The role of CDs in the enantioselectivity of the reactions with the participation of these complexes can be explained by preorganization of the substrates in the hydrophobic cavity and specific exposure of the reaction affected groups to the metal-catalytic part of the complex.

Thus, Schlatter et al. suggested [10] the application of ruthenium complexes of the amino alcohol $\beta$-CDs as catalysts in enantioselective reduction of aromatic and aliphatic ketones. The synthetic pathway for obtaining these complexes is presented in Scheme 1.

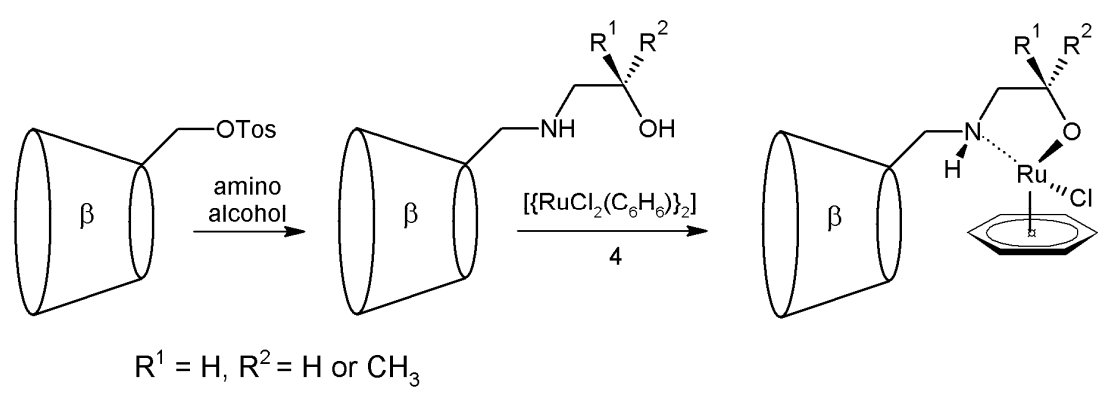

Scheme 1. Synthesis of Ru complexes of the amino alcohol $\beta$-cyclodextrins (CDs), adapted from [10].

According to Schlatter et al., the enantioselective excess values in the reactions of ketones' reduction with the application of Ru-cyclodextrin catalysts reaches $97 \%$ with acceptable yields from $51 \%$ to $90 \%$. Noteworthy is the fact that the use of the cyclodextrin-prolinol-Ru complex as a potential catalyst failed, suggesting the importance of the $-\mathrm{N}-\mathrm{H}$ group for hydrogen transfer to the carbonyl group. The reaction mechanism is presented in Scheme 2 bellow.

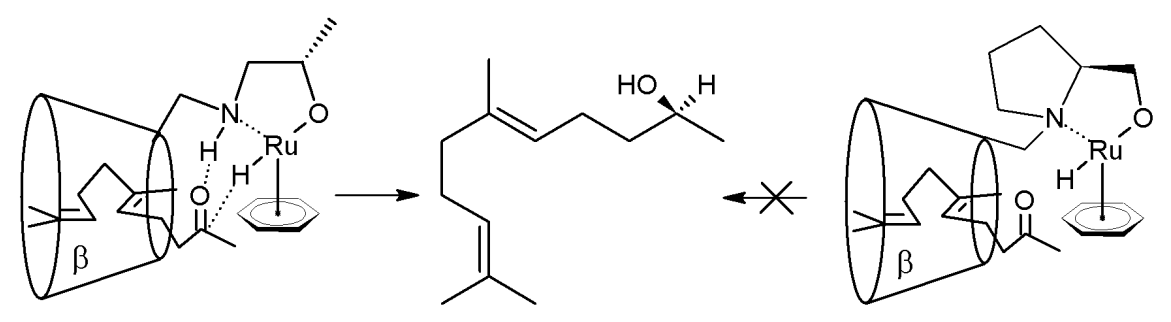

Scheme 2. Potential mechanism of hydrogen transfer from the Ru-hydride intermediate to geranyl acetone encapsulated in $\beta-\mathrm{CD}$, adapted from [10].

Shen and $\mathrm{Ji}$ [11] proposed a group of catalysts based on $\left[\mathrm{RuCl}_{2} \text { (benzene) }\right]_{2}$ and $\left[\mathrm{RuCl}_{2} \text { (mesitylene) }\right]_{2}$ cores with eight amino alcohol-modified $\beta$-CD-based ligands as another way for the reduction of aromatic ketones. The authors have observed the influence of aromatic ligands' volume on the enantioselectivity in the asymmetric hydrogenation of acetophenone: the enantioselectivity increased when the aromatic ligands were changed from "benzene" to "mesitylene" with larger molecular volume. This observation was explained by the increase in steric hindrance around the metal ion that prevented the substrate from conducting intermolecular catalytic hydrogenation. For the best artificial metalloenzymes with the $\left[\mathrm{RuCl}_{2} \text { (mesitylene) }\right]_{2}$ core, high levels of optical yields were achieved: $76 \%$ ee for the reduction of acetophenone and $80 \%$ ee for the reduction of 2-acetylnaphthalene.

In another example, Sakuraba et al. [12] proposed $\mathrm{Mo}(\mathrm{V})$ and $\mathrm{Cu}(\mathrm{II})$ complexes with $\beta$-CD derivatives having a catechol-type ligand (2,3- and 3,4-dihydroxy groups on the benzoate ring). Their 
chiral catalytic activity was examined in the asymmetric oxidation of aromatic sulfides with hydrogen peroxide in water ( $\mathrm{pH}$ 6.0). It appeared that the use of the $\mathrm{Mo}(\mathrm{V})$ complexes with the catechol derivatives yielded sulfoxides with $35 \%-65 \%$ ee, while the use of the $\mathrm{Cu}$ (II) complexes gave products with the opposite configuration at $26 \%-52 \%$ ee. The highest optical yield, $65 \%$, was observed in the oxidation of butyl phenyl sulfide using the catalytic amount $(0.1$ equiv) of the $\mathrm{Mo}(\mathrm{V})$ complex with mono-6-O-(3,4-dihydroxybenzoyl)- $\beta$-CD. The reaction gave predominantly the $(S)$-sulfoxide in a $95 \%$ chemical yield. The authors observed an interesting result in the induced chiralities of the products: in certain reactions, the reverse chiral induction appeared between the two metals coordinated by the same $\beta$-CD ligand. This observation was explained by the fact that two phenolic hydroxy groups attached at different positions $(2,3-$ and 3,4-) on the phenyl ring of the $\beta$-CD ligands induce the opposite chiral environment in or around the cavity of the modified $\beta$-CDs.

Wong et al. [13] have synthesized a rhodium complex with 6A,6B-bis(diphenylphosphino)-6A,6Bdideoxy-permethylated- $\beta$-cyclodextrin $\left(\left[\mathrm{Rh}(\mathrm{COD})\left(6 \mathrm{~A}, 6 \mathrm{~B}-\mathrm{PM}-\beta-\mathrm{CDP}_{2}\right)\right] \mathrm{BF}_{4}\right)$ (Scheme 3$)$, which appeared catalytically active for the hydrogenation of unsaturated acids ( $R$-acetamidocinnamic, $R$-acetamidoacrylic, itaconic) and their methyl esters with optical yields up to $92 \%$ ee.

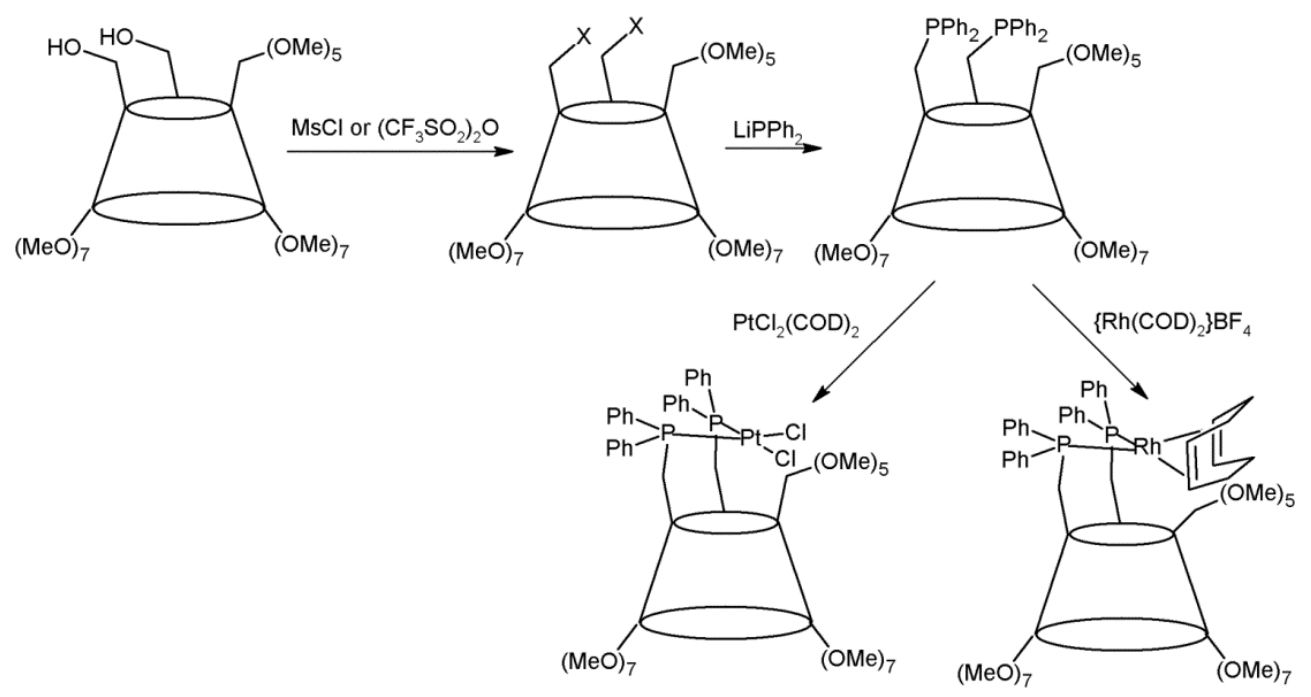

Scheme 3. Synthesis of rhodium complex with 6A,6B-bis(diphenylphosphino)-6A,6Bdideoxy-permethylated- $\beta$-cyclodextrin, adapted from [13].

Similar complexes were synthesized by Jouffroy et al. [14] based on hybrid phosphane-phosphite ligands obtained by regioselective A,B-functionalization of a methylated $\alpha$-cyclodextrin. Rhodium complexes of the CDs were used in asymmetric hydrogenation of $\alpha$-dehydroamino acid esters and hydroformylation of styrene. Poor enantiodiscrimination was reported for the highly mobile chelate complexes, while for the more rigid ones, ee values reached up to $92 \%$. The authors have concluded that the best performing hydrogenation catalyst in these experiments is the one in which both chiral components, CD and $(S)$-binaphthyl, behave in a synergistic way.

Yang et al. [15] proposed a manganese-porphyrin-based catalyst carrying $\beta$-CD binding groups capable of hydroxylating selective steroidal substrates with high regio- and stereo-selectivity and catalytic turnovers. It has also been concluded that the geometries of the complexes override the intrinsic reactivities, preventing oxidation of an otherwise reactive secondary carbinol or of a carbon-carbon 
double bond. The authors claim to achieve $100 \%$ conversion in the steroid hydroxylation reactions (Scheme 4) with catalyst turnovers reaching hundreds and even thousands. The selectivity effects, achieved this way, can be compared to enzymatic efficiency.
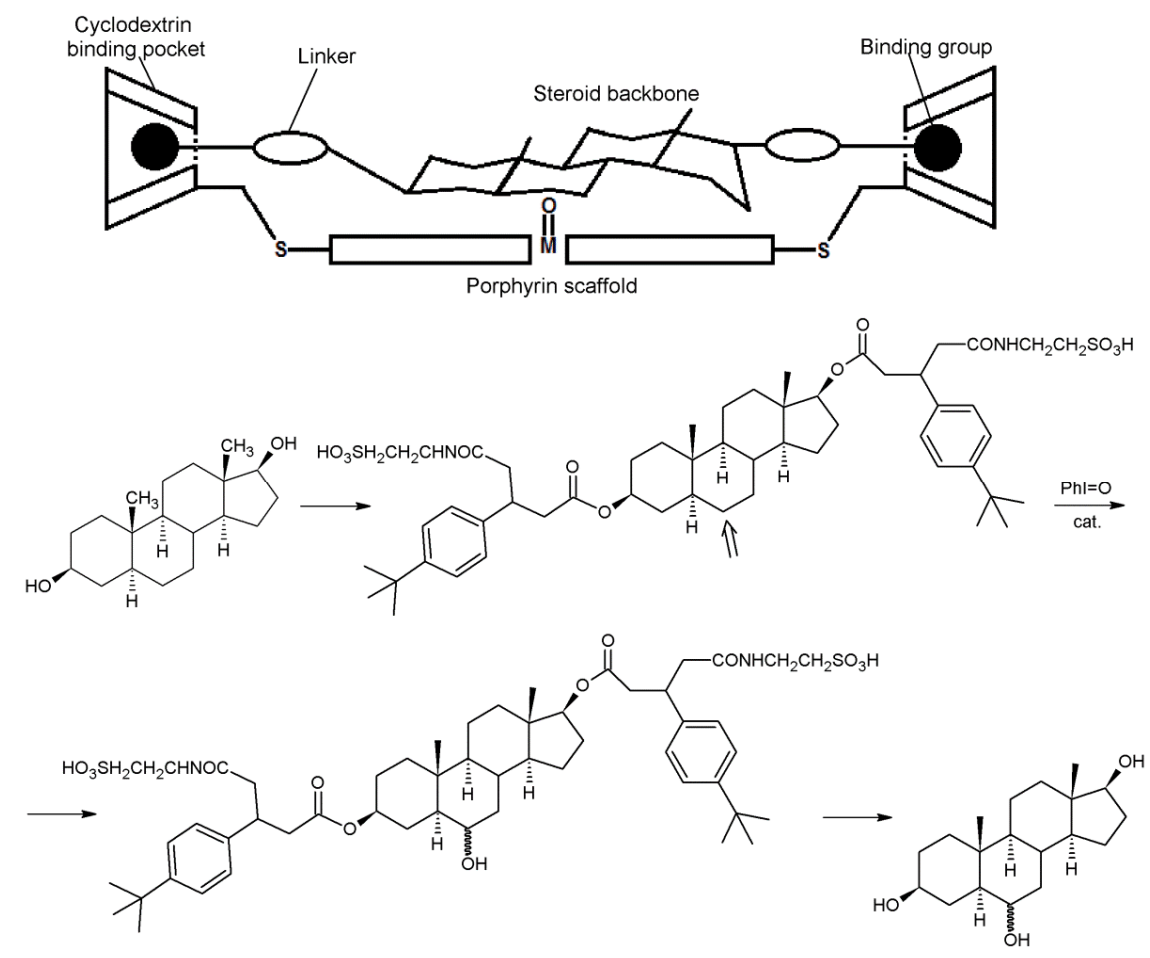

Scheme 4. Selective hydroxylation of steroidal substrate with manganese-porphyrin-based catalyst carrying $\beta$-CD binding groups, adapted from [15].

High enantioselectivity has been demonstrated by Engeldinger et al. [16] in the reaction of hydrogenation of dimethyl itaconate with the $\mathrm{Rh}(\mathrm{I})$ complex with difunctionalized $\alpha$-CD bearing AD-positioned triarylphosphite ligands. The reaction resulted in the formation of $(R)-(+)$-methylsuccinate with an ee of $84 \%$. The authors suggested that the entrapment and favorable orientation of the olefinic substrate in the catalytic complex is favored by the fact that the chiral cavity of the cyclodextrin is rigidly positioned near the metal center; thus, a good level of enantioselectivity is induced.

Cassez et al. [17] suggested that application of cyclodextrins in the palladium-charcoal-catalyzed Heck reaction leads to multiple advantages. They have demonstrated that the use of randomly-methylated beta-cyclodextrin (RaMe- $\beta-\mathrm{CD}$ ) affects the catalytic sites of $\mathrm{Pd} / \mathrm{C}$ contributing greatly to the increase of the reaction's chemo- and stereo-selectivity. The stereoselectivity, in this case, is greatly influenced by the cyclodextrin's cavity size (number of glucopyranosyl units in the cyclodextrin molecule): the formation of the $E$-isomer increases when the cavity size decreases. Besides that, the authors assumed that as a result of $\mathrm{CD}$ adsorption on the $\mathrm{Pd} / \mathrm{C}$ surface, the dispersion of the $\mathrm{Pd} / \mathrm{C}$ particles in water has increased due to their more hydrophilic character, a factor that also contributed to higher catalytic activity.

Concomitantly, Senra et al. reported [18] the positive influence of 2-hydroxypropylcyclodextrins (HPCDs) on the stereoselectivity of aqueous Heck coupling and hydroarylation catalyzed by $\mathrm{Pd}-\mathrm{CaCO}_{3}$. In addition to previous authors, Senra et al. detected that the decrease of CD's cavity size leads to higher stereoselectivity of the reaction. They also suggested that the significant number of hydroxyl groups characteristic for CDs also plays an important role in the reduction of $\mathrm{Pd}(\mathrm{II})$ species from $\mathrm{Pd} / \mathrm{CaCO}_{3}$. 
Shen and Ji [19] have reported obtaining several amino alcohol-modified $\beta$-CDs and their complexes with sodium molybdate with their following application in the asymmetric oxidation of thioanisole (Scheme 5). For the methyleneaminoethanol derivative of $\beta-\mathrm{CD}$, a moderate enantioselectivity (56\% ee) was achieved in aqueous $\mathrm{CH}_{3} \mathrm{COONa}-\mathrm{HCl}$ buffer solution ( $\mathrm{pH} 7.0$ ). It has also been detected that the ability of these complexes to induce asymmetry is highly dependent on the $\mathrm{pH}$ value of the reaction medium and the structure of the modifying group. The moderate enantioselectivity has been attributed to two different binding models between $\mathrm{CD}$ and thioanisole, which could be defined as intramolecular catalysis and intermolecular catalysis. Thus, while intramolecular catalysis gave $(S)$-methyl phenyl sulfoxide, the intermolecular catalysis gave $(R, S)$-methyl phenyl sulfoxide.

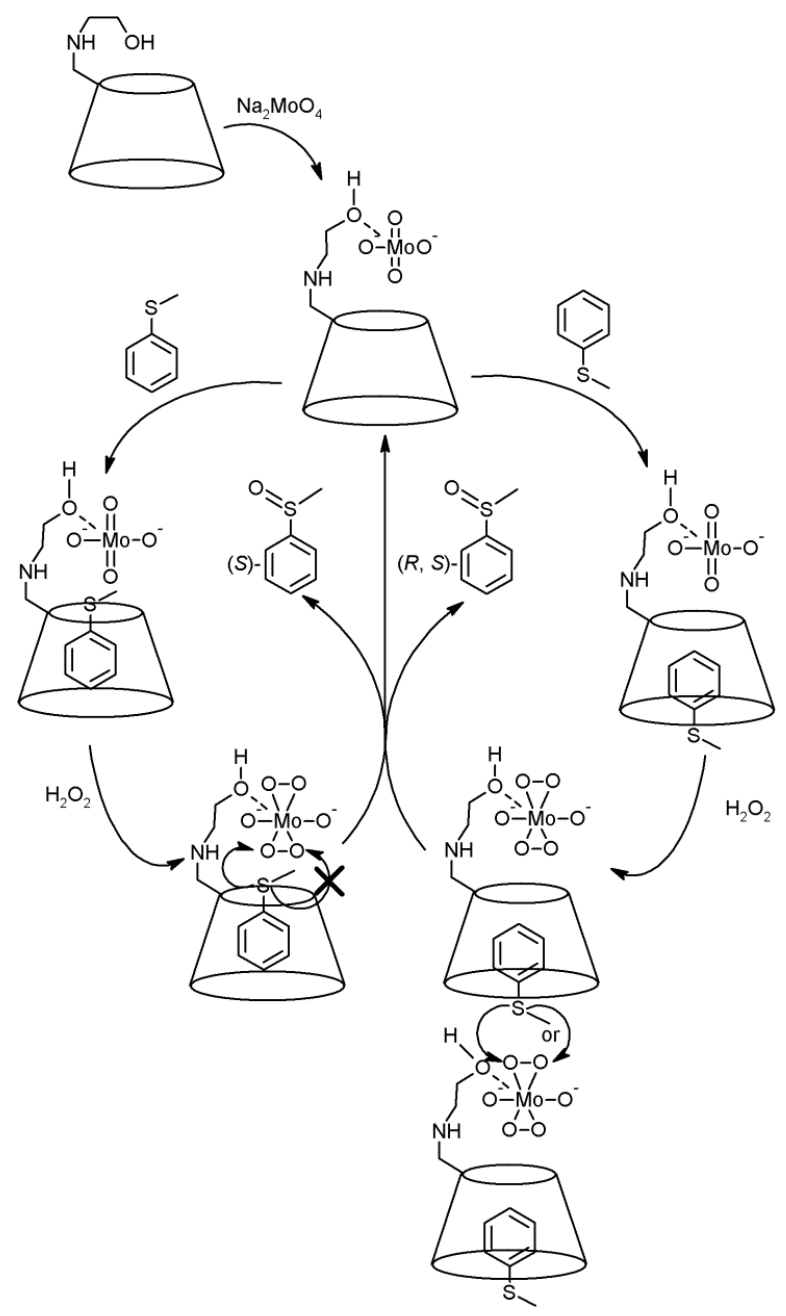

Scheme 5. Proposed catalytic cycle of the asymmetric oxidation of thioanisole in the presence of molybdate-methyleneaminoethanol $\beta$-CD complex, adapted from [19].

Jouffroy et al. [20,21] have reported obtaining cyclodextrin-based cavity-shaped ligands to generate exclusively singly-phosphorus-ligated complexes. Such complexes with rhodium when being used to catalyze the hydroformylation of styrene led to high iso-regioselectivity and stereoselectivity (Scheme 6). In the case of this catalyst, iso-regioselectivity increases concomitantly with enantioselectivity, an observation that the authors explain through differences in the behavior between singly-phosphine-ligated active species and the usual (bis)phosphine complexes. The authors also claim that the observed enantio- and iso-regioselectivities are among the highest reported for the asymmetric hydroformylation of styrene. 


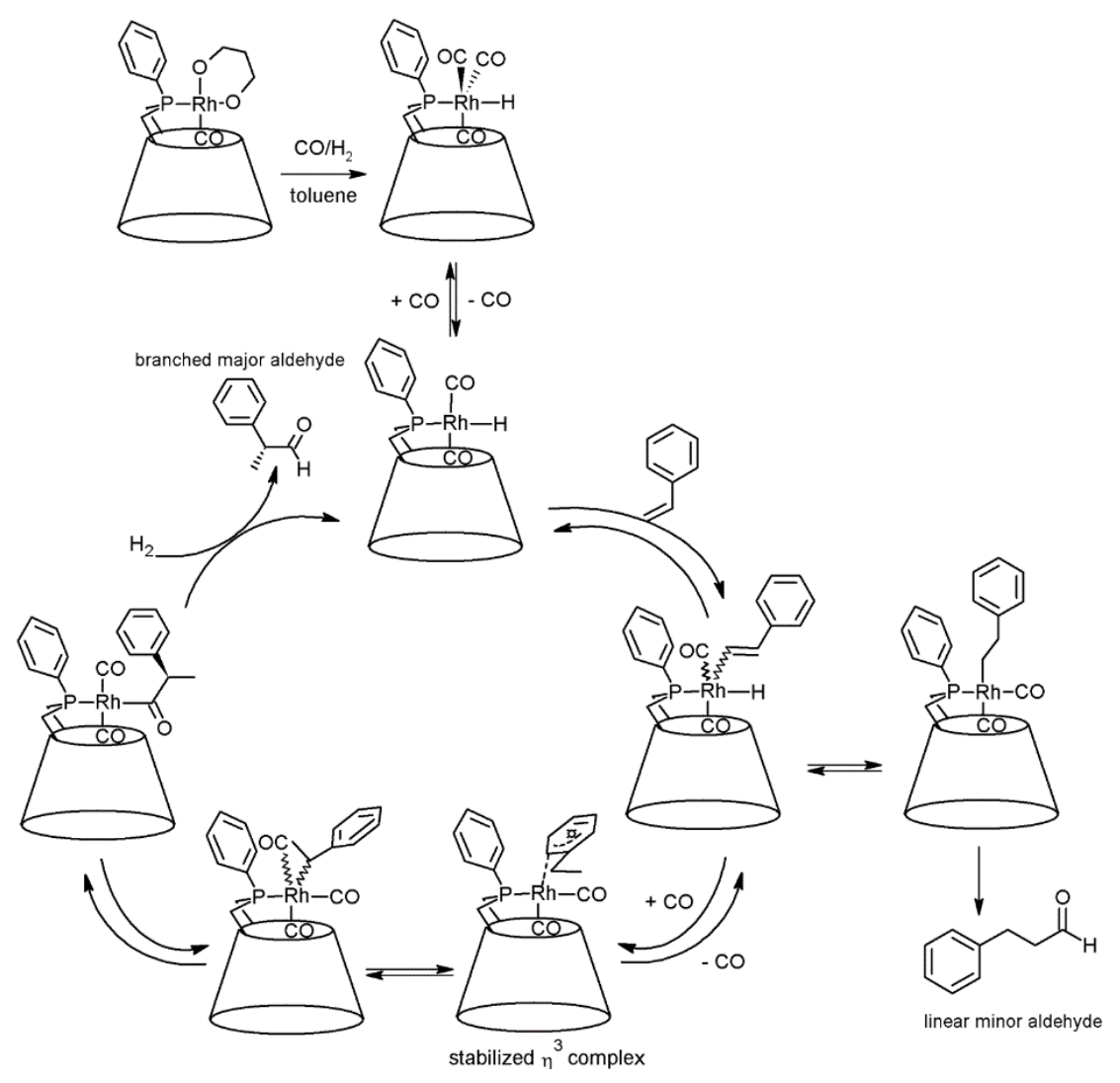

Scheme 6. Proposed catalytic cycle of asymmetric hydroformylation of styrene in the presence of cyclodextrin-based monophosphine rhodium complexes, adapted from [21].

\subsection{Cyclodextrins'Non-Metallic Derivatives as Asymmetric and Stereospecific Catalysts}

A large variety of stereospecific and asymmetric reactions have been performed with the application of non-metallic derivatives of cyclodextrins.

Among the first, a high level of enantiomeric selectivity in halogenation and hydrohalogenation reactions in solid cyclodextrin complexes has been reported by Tanaka et al. [22]. The group managed to achieve $88 \%$ and $100 \%$ optical yield in chlorination of methacrylic acid in complexes with $\alpha$-CD and $\beta-C D$, respectively. The group suggested that the attack of a halonium cation on the molecule included into the cyclodextrin cavity is more likely to take place from the side facing the wider opening than from that facing the narrower opening of the torus.

Later, the same group performed asymmetric halogenation and hydrohalogenation of other alkenes in solid complexes with cyclodextrins, reaching different levels of optical yields: $88 \%$ in the chlorination of maleic acid in complex with $\beta$-CD [23], 40\% in the bromination of trans-cinnamic acid in complex with $\beta$-CD [24], 46\% $(R)$ in the hydrobromination of ethyl trans-cinnamate in complex with $\alpha-C D$ and $31 \%(S)$ in complex with $\beta$-CD [23], 14\% $(S)$ and $8 \%(S)$ in the chlorination of styrene in complex with $\alpha-\mathrm{CD}$ and $\beta-\mathrm{CD}$, respectively [25], 58\% $(S)$ in the hydrochlorination and $64 \%(S)$ in the hydrobromination of trans-2-butenoic acid in complex with $\alpha$-CD [26]. The authors suggest that the main mechanism for the hydrohalogenation of crystalline trans-2-butenoic included in the cyclodextrin cavity begins with the protonation of the doubly-bonded oxygen atom of the carboxyl group of the guest molecule by attack of the hydrogen ion from the hydrogen halide. Afterwards, the guest molecule moves 
along the longitudinal or $Z$ axis of the cavity through simultaneous hydrogen bond cleavage. The halide anion then easily enters the cavity from the wider side of the secondary hydroxyl groups and then attacks the third carbon atom of the guest, located in the wider opening side of the host.

Asymmetric bromination of chalcone and benzylideneacetone (trans-isomers) in crystalline $\beta$-CD were studied by Pitchumani et al. [27]. They determined that bromination of the $\beta$-CD-chalcone complex results in the formation of a mixture of erythro- and threo-dibromides, respectively, in a ratio of 80:20, while bromination of chalcone in the absence of $\beta$-CD yields only erythro-dibromide. Complexation of trans-benzylideneacetone with $\beta-C D$ does not induce any variation in its bromination pattern. These observations have been explained by different conformations of the enones in the $\beta$-cyclodextrin-enone complexes.

Per-6-amino- $\beta$-cyclodextrin (PA- $\beta$-CD) has been shown to be a highly efficient catalyst in the one-pot synthesis of enantiomerically-enriched 2-aryl-2,3-dihydroquinolin-4 $(1 \mathrm{H})$-ones with high yield (up to $99 \%$ ) and enantiomeric excess (up to 99\%). The catalyst can be easily recovered and reused without loss in its activity [28]. Earlier, this group applied PA- $\beta-C D$ for the Henry (nitroaldol) reaction [29], a carbon-carbon bond-forming reaction that can be used to create a new stereogenic center at the $\beta$-position of nitro functionality. PA- $\beta$-CD was used as a chiral base and a host for the addition of nitromethane (3)/nitroethane (5) to substituted aldehydes in $\mathrm{ACN} /$ water $(1: 1 \mathrm{v} / \mathrm{v})$ medium at $-20{ }^{\circ} \mathrm{C}$ with $<99 \%$ ee. The proposed mechanism for this reaction is presented in Scheme 7.

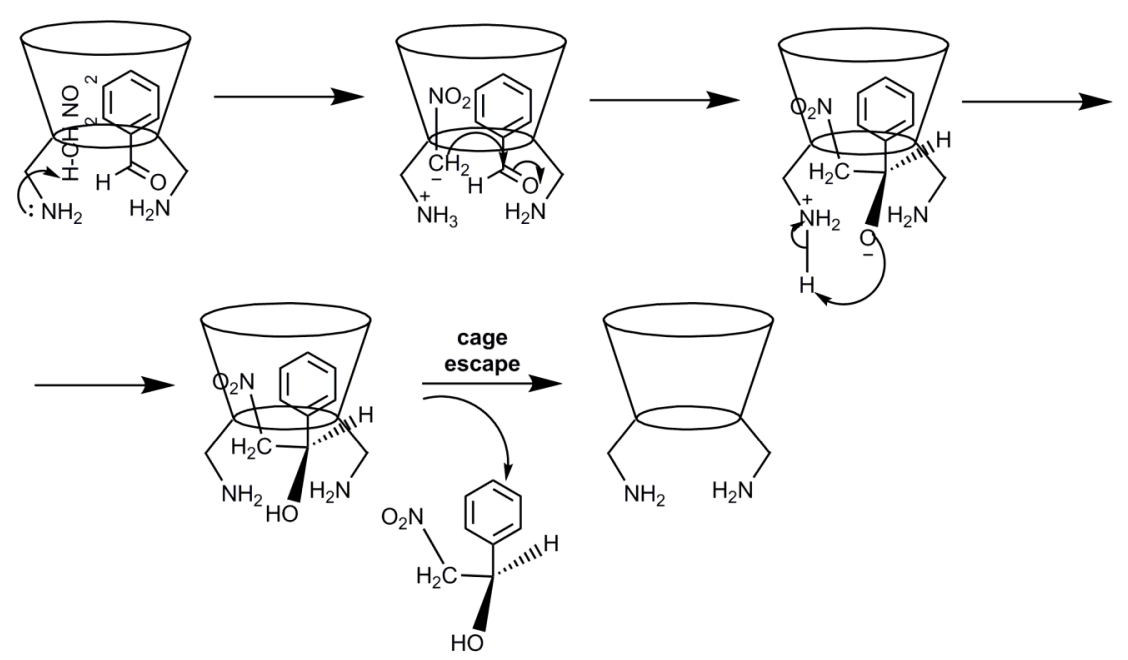

Scheme 7. Proposed mechanism for the asymmetric Henry reaction promoted by per-6-amino- $\beta$-cyclodextrin (PA- $\beta$-CD), adapted from [29].

Moreover, the group used PA- $\beta-C D$ for enantioselective Michael addition of nitromethane/thiols to trans-chalcone [30]. The reaction was carried out in water at room temperature with a good yield and enantiomeric excess. In the case of nitromethane addition, the yield was $100 \%$ and enantiomeric excess up to $69 \%$. The catalyst reusability test demonstrated stable $100 \%$ reaction yield after three runs; however, in the third run, the enantiomeric excess decreased considerably. The proposed mechanism for this reaction is presented in Scheme 8.

In the case of thiols' addition to chalcones in the same conditions as the previous reaction, Suresh and Pitchumani reported reaction yields from $50 \%$ to $100 \%$ and enantiomeric excess of $4 \%-61 \%$ [30]. 

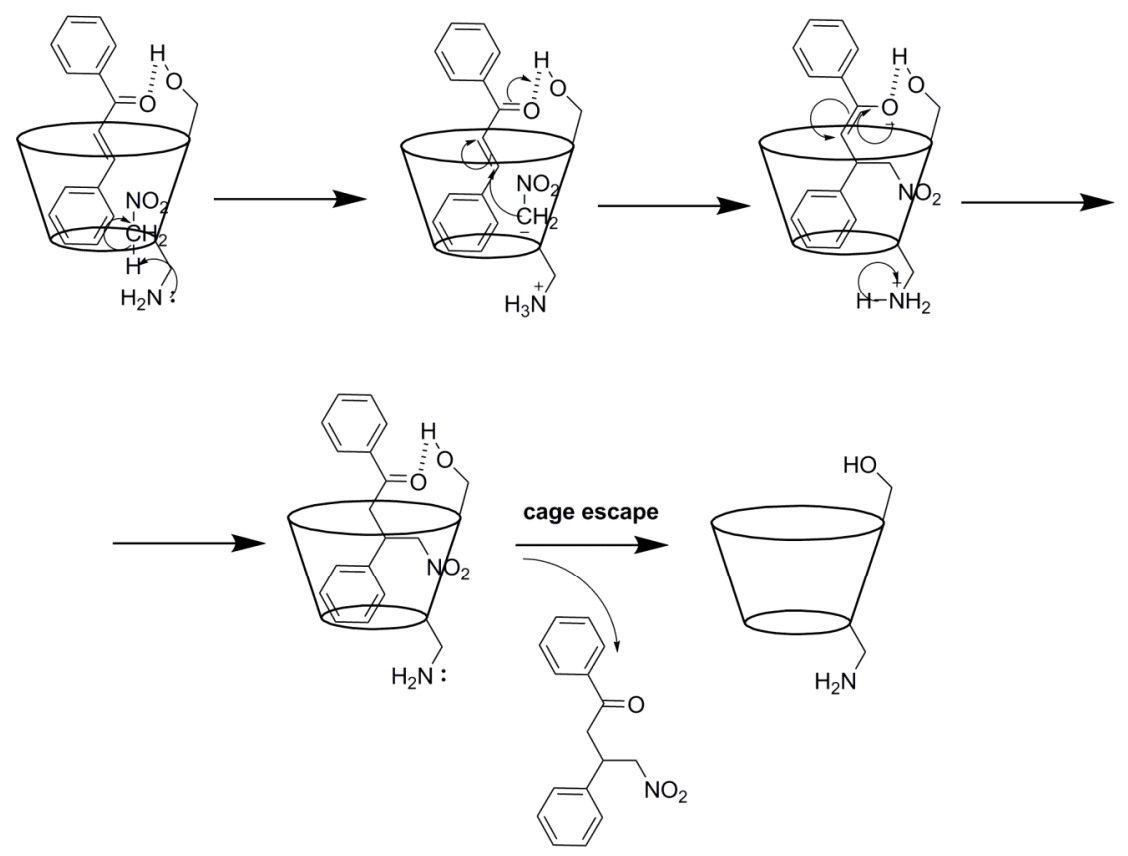

Scheme 8. Proposed mechanism for asymmetric Michael addition catalyzed by PA- $\beta-C D$, adapted from [30].

CDs and their derivatives have been long successfully used for the asymmetric reduction of ketones to chiral alcohols. The first published study was the CD-mediated asymmetric reduction of aryl trifluoromethyl ketones with $\mathrm{NaBH}_{4}$ in an alkaline aqueous solution of sodium cholate micelle [31]. Optically-active carbinols were obtained in $0 \%-10 \%$ ee in the presence of $\beta-C D$ at a molar ratio $\beta-\mathrm{CD} /$ substrate $=10 / 1$. The optical yield of the reduction process very often varies in dependence of the cyclodextrin, ketone and conditions of the reduction reaction. Thus, the highest ee reached by Fornasier et al. [32] reducing $\beta$-CD-ketone complex in a sodium borohydride $\left(\mathrm{NaBH}_{4}\right)$ aqueous alkaline solution was 32\%. Higher optical yields were achieved by Sakuraba et al. [33] in the reduction of aromatic ketones by crystalline amine-boranes-CD complexes (91\% ee) and by Kawajiri et al. [34] in the reduction of ferrocenyl ketones (Scheme 9) by crystalline $\mathrm{NaBH}_{4}-\mathrm{CD}$ complexes as reduction agents in the presence of alkaline salts $(84 \%$ ee).

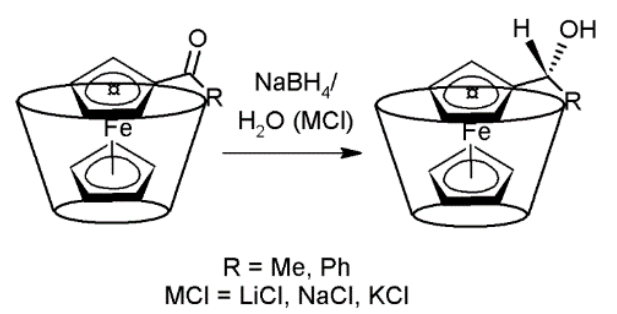

Scheme 9. Asymmetric reduction of ferrocenyl ketones, adapted from [34].

A high level of enantioselectivity in the reduction of benzoylformic acid (BFA) using $\mathrm{NaBH}_{4}$ has been reported using 6-amino-6-deoxy- $\beta$-CD (ACD) as the host in place of $\beta$-CD in neutral aqueous buffer solution [35,36].

Investigation of the asymmetric reduction of indol-3-pyruvic acid (IPA) with $\mathrm{NaBH}_{4}$ in aqueous solution in the presence of various cyclodextrins $(\alpha-, \beta-, \gamma-$, mono-6-amino-6-deoxy- $\beta-$ and 
di- $6^{\mathrm{AB}}$ amino- $6^{\mathrm{AB}}$-deoxy- $\beta$-cyclodextrin) has demonstrated that part of the carboxylic group stays in the cavity of $\alpha-C D$, one whole IPA molecule in $\beta-C D$, two molecules in the $\gamma-C D$ cavity and IPA(s) is (are) attached to the rim of the cavity of mono-6-amino- 6 -deoxy- $\beta$ - and di- $6^{\mathrm{AB}}$ amino- $6^{\mathrm{AB}}-\mathrm{deoxy}-\beta-\mathrm{CD}$ (A- $\beta-C D, D A-\beta-C D)$ with electrostatic interaction between amino and carboxylic groups (Figure 1). Depending on the type of cyclodextrin involved, different optical selectivity has been observed, as can be seen from the results presented in the Table 1 [37].

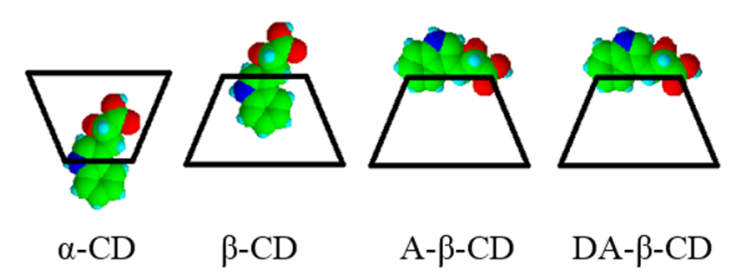

Figure 1. Asymmetric reduction of indol-3-pyruvic acid (IPA) acid carried out in the presence of different CDs, adapted from [37].

Table 1. Results of the asymmetric reduction of indol-3-pyruvic acid (IPA) with $\mathrm{NaBH}_{4}$ in aqueous solution in the presence of various cyclodextrins [37].

\begin{tabular}{cccc}
\hline Substrate & Cyclodextrin & Optical yield\%/ee & Configuration \\
\hline IPA & none & 3 & $\mathrm{~S}$ \\
& $\alpha-\mathrm{CD}$ & 1 & $\mathrm{~S}$ \\
& $\beta-\mathrm{CD}$ & 6 & $\mathrm{~S}$ \\
& $\gamma-\mathrm{CD}$ & 0 & - \\
& $\mathrm{A}-\beta-\mathrm{CD}$ & 17 & $\mathrm{R}$ \\
& $\mathrm{DA}-\beta-\mathrm{CD}$ & 33 & $\mathrm{R}$ \\
\hline
\end{tabular}

Tang et al. [38] used $\mathrm{NaBH}_{4}$ in the presence of a chiral $\beta$-CD-based ionic liquid, mono-6-(1-methyl-3-imidazolium)-6-deoxy- $\beta$-cyclodextrin tosylate (MIM- $\beta$-CDOTs), for stereoselective reduction of acetophenones (Scheme 10). It has been found that the structure of the acetophenone derivatives influences the optical yield of the alcohols, most probably through the influence on the cyclodextrin inclusion process. Moreover, it has been shown that the optical yields of the resulting alcohols also depend on the reaction temperature: ee significantly increased with a decrease of the reaction temperature. Wan et al. [39] studied the interaction between acetophenone and $\beta$-CD in the complex and confirmed that acetophenone inserts into the cavity mainly from the secondary hydroxyls side. The results of the hydrogen bonds analysis confirmed the donor-acceptor interactions in the complex; while ${ }^{13} \mathrm{C}$ NMR results showed that the active site concentrates on the carbon atom of the carbonyl group.

Asymmetric reduction of $\alpha$-azido-aryl ketones to corresponding alcohols with the application of sodium borohydride in water has been reported by Reddy et al. [40] to be efficiently catalyzed by $\beta-C D$ (Scheme 11). The obtained compounds have been shown to have an $S$ configuration. Interestingly, in the case of the initial substrates with electron donating substituents on the aromatic ring, a higher enantioselectivity has been observed as compared to the substrates with the electron withdrawing substituents. Other important factors that influence the asymmetric reduction of $\alpha$-azido-aryl ketones in water in the presence of CDs include: hydrophobic binding, carbonyl exposure to the $\mathrm{CD}$ rim of 
secondary hydroxyl groups, the formation of hydrogen bonds with a consequent decrease in the degrees of freedom of the guest molecule, favorable control of the geometry in the approach of the substrate to the "active site", etc. The yields of the reaction ranged from $90 \%$ to $96 \%$ with enantioselectivity reaching up to $81 \%$.

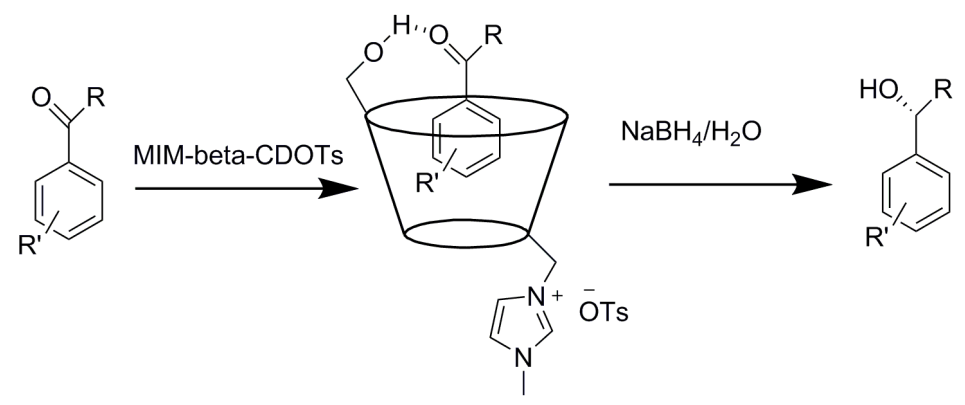

Scheme 10. Enantioselective reduction of acetophenones, adapted from [38]. MIM- $\beta$-CDOT, mono-6-(1-methyl-3-imidazolium)-6-deoxy- $\beta$-cyclodextrin tosylate.

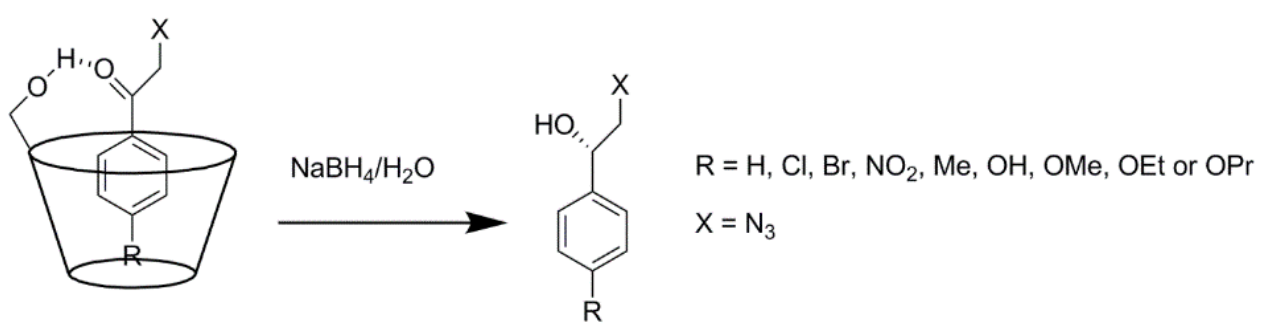

Scheme 11. Enantioselective reduction of $\alpha$-azido-aryl ketones, adapted from [40].

The stereoselective and enantioselective effects of $\beta-C D$ and its derivatives, in the hydrogenation of $(2 S, 5 R)-(-)$-menthone, have been reported by Ravichandran [41]. The process was performed in the presence of catalysts: Raney Ni and alkali. In this reaction, the orientation of guest molecules inside the $\beta-\mathrm{CD}$ cavity and the orientation of the inclusion complex as a whole with respect to the catalytic $\mathrm{Ni}$ surface both enhance the process selectivity. While the reduction did not occur in the absence of alkali, it yielded only $36 \%$ alcohols in the presence of it. The presence of both $\beta$-CD and alkali showed remarkable selectivity, reaching a menthol/neomenthol ratio equal to 4.8 , the total alcohols' yield being almost quantitative: $99.7 \%$.

Among the first, stereoselective oxidation of sulfides into sulfoxides by hydrogen peroxide catalyzed by $\beta-C D$ was studied by Drabowicz and Mikołajczyk [42]. The highest ee of 30\% was obtained for phenyl butyl sulfide oxidation with hydrogen peroxide in pyridine and in the presence of $\beta$-CD during 214 h. At the same time, Czarnik [43] reported chiral oxidation of sulfides in the presence of $m$-chloroperoxybenzoic acid (m-CIPBA), tert-butyl peroxide (TBHP) and phenyliodonium diacetate (PIDA) and catalyzed by $\alpha-, \beta$ - and $\gamma-\mathrm{CD}$ (Scheme 12). The best enantioselectivity was observed in the oxidation of ethyl 3-tert-butylphenyl sulfide catalyzed by $\beta$-CD and reached $33 \%$ in the presence of $m$-CIPBA at $4{ }^{\circ} \mathrm{C}, 20 \%$ in the presence of TBHP and $26 \%$ in the presence of PIDA as the oxidizing agent. Later, Rao and Sattur [44] reported a good ee of up to $53 \%$ in obtaining optically-active $\alpha, \alpha$-dichlorosulfoxides by the oxidation of substituted thioacetates with sodium hypochlorite in water. 


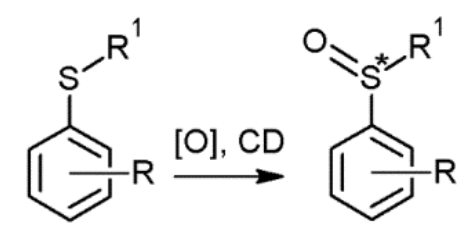

Scheme 12. Asymmetric oxidation of sulfides, adapted from [44].

Later, Sakuraba et al. [45] performed enantioselective oxidation of alkyl aryl sulfides in crystalline $\mathrm{CD}$ complexes under various conditions. The oxidation of alkyl phenyl sulfoxides in the $\beta-\mathrm{CD}$ complexes resulted in higher chiral induction than that in the $\alpha-\mathrm{CD}$ complexes. Methyl 1- or 2 -naphthyl sulfides were oxidized more enantioselectively in $\beta$-CD than in $\gamma$-CD. The reaction of the $\gamma$-CD complex increased the chiral induction reversely after the methyl substituent of 1-naphthyl sulfide had been changed to an isobutyl group. The highest optical yield, $81 \%$, was achieved in the combination of peracetic acid and methyl 1-naphthyl sulfide in the crystalline $\beta$-CD complex suspended in water at the oxidizing conditions of $0{ }^{\circ} \mathrm{C}$ under nitrogen, which resulted in the formation of the $(S)$-(-)-sulfoxide in a high chemical yield without the formation of sulfone. It could be suggested that enantioselectivity of the sulfides' oxidation in these conditions depends on the size of the hydrophobic cavity of CDs and requires a rigid fixation of the guest molecule in it. In addition, as reported by Fornasier et al. [46], precomplexation of reactant with CD significantly impacts the enantioselectivity of oxidation.

Deary and Davies [47] have reported obtaining derivatized HPCDs that are capable of catalyzing the peroxymonosulfate (PMS) oxidation of a range of substrates, including aryl alkyl sulfoxides, pyridine, 4-bromopyridine, aniline, 4-aminobenzoate, 4-bromoaniline and several amino acids, most probably by the formation of a more reactive cyclodextrin-dioxirane intermediate. They have managed to observe a small degree of enantioselectivity in the oxidation of $(R)-(+)$ - and $(S)-(-)$-methyl $p$-tolyl sulfoxide by PMS in the presence of the keto derivative of hydroxypropyl- $\alpha$-cyclodextrin, though not for the $\beta$ analogue.

In recent years, a series of pteridine derivatives-cyclodextrin conjugates for enantioselective oxidation of prochiral aromatic and aliphatic sulfides with hydrogen peroxide has been studied [48-50]. The highest optical yield achieved with these catalysts was $91 \%$ ee. The conjugates usually contained flavin, isoalloxazine or alloxazine moieties attached to the primary rim of $\alpha$ - and $\beta$-CDs in the position C- 6 . Stereodiscrimination in oxidation reactions catalyzed by different pteridine derivatives is induced by the $\pi-\pi$ interaction between the oxidant (pteridine derivative hydroperoxide) and the substrate, while conjugation with cyclodextrins induces the enhancement of stereodiscrimination properties in the resulting systems.

The asymmetric epoxidation of vitamin K3 (Scheme 13) and analogues in aqueous alkaline buffer solution or in $\mathrm{DMF} /$ solid $\mathrm{Na}_{2} \mathrm{CO}_{3}$, in the presence of $\alpha$ - and $\beta-\mathrm{CD}$, has been investigated by Colonna et al. [51]. It has been demonstrated that among them, the presence of a hydrophobic chain of suitable length in the substrate and a decrease of the degrees of freedom in the substrate-cyclodextrin and possibly also in the oxidant-cyclodextrin interactions seem to play an important role. These favorable effects are optimal for 2-octyl-1,4-naphthoquinone, but a further increase of the alkyl chain destroys the delicate balance. Consequently, epoxidation of 2-octyl-1,4-naphthoquinone in the presence of $\alpha$-CD in $\mathrm{DMF} / \mathrm{Na}_{2} \mathrm{CO}_{3}$ results in a chemical yield of $61 \%$. 


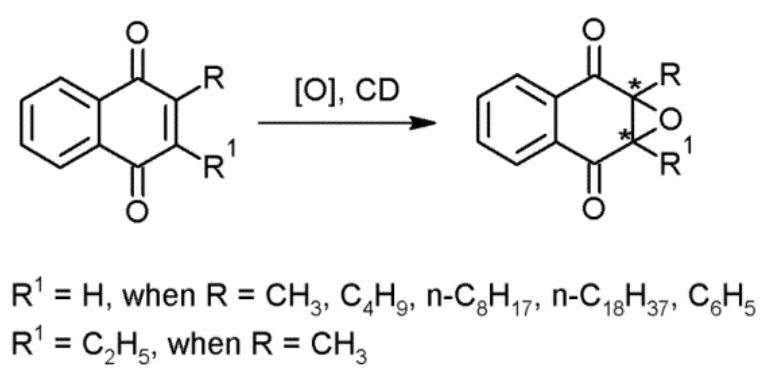

Scheme 13. Asymmetric epoxidation of vitamin $\mathrm{K}$ derivatives in the presence of $\mathrm{CD}$, adapted from [51].

Chan et al. [52] have proposed the application of a ketoester derivative of $\beta$-CD (Figure 2a) in the stereoselective epoxidation of alkenes. The epoxidation of $(S)$ - $\alpha$-terpineol mediated by the obtained catalyst produced terpineol oxides in high yields and stereoselectivity (i.e., cis-/trans-epoxide ratio) decreasing from 2.5:1 down to 1:1.2 with an increase of the steric bulkiness of the terpenes. Use of the same catalyst (20-50 mol\%) in enantioselective epoxidation of styrenes, carried out in aqueous acetonitrile solution, resulted in $40 \%$ ee in the case of 4-chlorostyrene epoxidation at $0{ }^{\circ} \mathrm{C}, 37 \%$ ee for 1,2-dihydronaphthalene, $36 \%$ ee for 4-chlorostyrene and $31 \%$ ee for trans-stilbene epoxidation, respectively. At the same time, Rousseau et al. [53] have reported moderate stereoselectivity (up to 12\%) in the epoxidation of alkenes in the presence of oxone catalyzed by $\alpha$ - and $\beta$-CD derivatives with the structures b-e presented in Figure 2 and, later [54], a better enantioselectivity of up to $45 \%$ with catalysts, Figure 2f,g. All authors demonstrated that the cavity size is important for the epoxidation rate and stereoselectivity, and it should correlate with the molecular dimensions of the substrate.

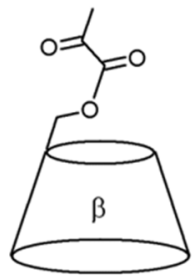

(a)

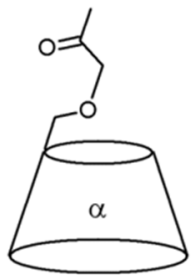

(b)

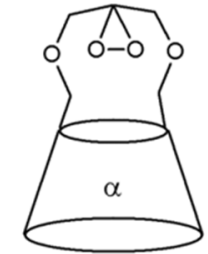

(c)

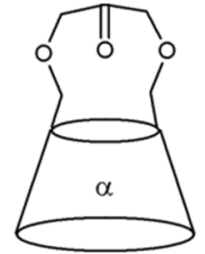

(d)

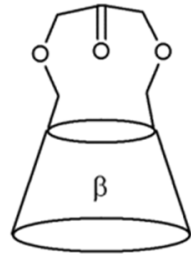

(e)

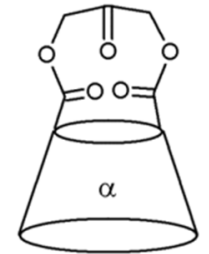

(f)

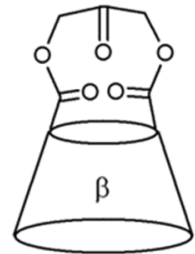

(g)

Figure 2. Structures of cyclodextrin catalysts for the epoxidation of alkenes as reported by: (a) Chan et al. [52]; (b-e) Rousseau et al. [53]; (f,g) Rousseau et al. [54].

Shen et al. [55] have proposed the immobilization of (4S)-phenoxy-( $S$ )-proline on $\beta$-CD to obtain an efficient and reusable catalyst for direct asymmetric aldol reactions. The authors have suggested that the interaction of the amino acid molecule with the chiral $\beta-\mathrm{CD}$ molecule changed the microenvironment around the catalytic center where the reaction proceeds and, therefore, improved the selectivity. In addition, they demonstrated that the product can be separated from the catalyst simply by filtration, and the catalyst can be recovered and reused conveniently. During the four cycles of catalyst reuse, the maximum chemical yield of the product around $90 \%$ was obtained during the first cycle and then reduced to about $80 \%$ at the fourth cycle. The enantioselectivity remained almost unchangeable around $83 \%$. 
Shen and Ji [56] further obtained (S)-2-aminomethylpyrrolidine- and $(R)$-2-aminomethylpyrrolidine-modified $\beta-C D$ as aldolase enzyme mimics. When applied to the asymmetric aldol reactions in water, the $(S)$-derivative exhibited excellent catalytic activity and enantioselectivity: up to $94 \%$ ee was achieved in a yield of $46 \%$. Recently, Liu and Zhang [57] have reported that covalently attaching proline to $\beta$-CD through a urea linkage resulted in obtaining a high yield of a water-soluble chiral organocatalyst that in a $5 \mathrm{~mol} \%$ concentration catalyzes asymmetric aldol condensations between aldehydes and acetone in water. The reaction takes place for a broad range of aldehydes with moderate to high yields and enantioselectivities (up to $99 \%$ ee). Good recyclability and reusability of the catalyst has been detected. The authors have noted a high level of substrate selectivity in these reactions. Correspondingly, enantioselectivities of the products decreased dramatically in the order of para-, meta- and ortho-substituted benzaldehydes. The group attributed the different stereoselectivities resulting from the aromatic substrates to their different binding abilities with the interior cavity of $\beta-\mathrm{CD}$ on the catalyst, consistent with the fact that the binding constants between substituted aromatics and $\beta-C D$ decrease in the same order.

Bonetto et al. [58] have described the enantioselective addition of diethylzinc to aldehydes, allylation and tert-butylation, promoted by alkylated CDs. Dialkylzinc derivatives are very effective alkyl donors to aldehydes in aprotic organic solvents. In the studied reaction, treatment of ferrocenylcarboxyaldehyde (Fc-CHO) with diethylzinc and heptakis $\left(2,3,6-\mathrm{O}, \mathrm{O}^{\prime}, \mathrm{O}^{\prime \prime}\right.$-trimethyl)- $\beta-\mathrm{CD}$ in degassed hexane-toluene $(1: 1)$ at room temperature produced a chiral secondary alcohol in $20 \%$ ee. $\beta-\mathrm{CD}$, heptakis $\left(2,3,6-\mathrm{O}, \mathrm{O}^{\prime}, \mathrm{O}^{\prime \prime}\right.$ trimethyl)- $\beta-C D$ and heptakis(2,6-O, $\mathrm{O}^{\prime}$-dimethyl-3-O-butyl)- $\beta-\mathrm{CD}$ also contributed to high enantioselectivity in the allylation and tert-butylation of 2-cyclohexanone using $\mathrm{Zn}$ dust and alkyl halides in a 5:1 water-THF solution. Thus, the reaction with tert-butyl bromide and heptakis(2,6-O,O'dimethyl-3-O-butyl)- $\beta$-CD raised the asymmetric induction to $50 \%$ ee [59].

Reddy et al. [60] have performed enantioselective preparation of $\beta$-aminoalcohols by dynamic kinetic resolution in an addition reaction between amines and racemic aryl epoxides in cyclodextrin complexes under solid state conditions (Scheme 14). The authors have proven that in order to get a single enantiomer in the product, an interconversion of one of the enantiomers of the initial epoxide is required. The conversion is possible through racemization, which is controlled by entropy effects. Thus, one of the enantiomeric forms of the epoxide in the $\beta-C D$ cavity, due to its favorable geometry, is captured selectively by the external amine, and the phenomenon of dynamic resolution takes place under the reaction conditions.

Later, Asahara et al. [61] also demonstrated that the kinetic resolution of primary amines is possible through enantioselective $\mathrm{N}$-acylation with acyl chlorides with selective sequestration of one enantiomer within the cyclodextrin cavity in nonpolar solvents.

Optically-active benzoin can be obtained by photolysis of solid $\beta$-cyclodextrin complexes of benzaldehyde according to Rao and Turro [62] with an enantiomeric excess of up to $15 \%$ (Scheme 15). The observed photochemical behavior of benzaldehyde-cyclodextrin complexes in the solid state is unique and different from that of the complexes in aqueous solution and from benzaldehyde in organic solvents. 


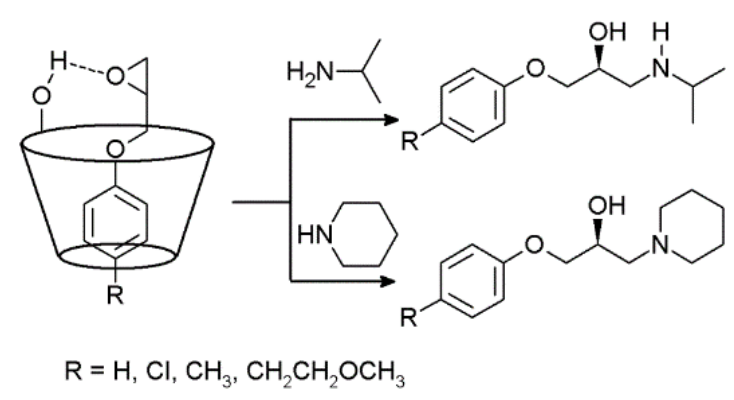

Scheme 14. Enantioselective preparation of $\beta$-aminoalcohols by dynamic kinetic resolution in a reaction between amines and racemic aryl epoxides in cyclodextrin complexes, adapted from [60].
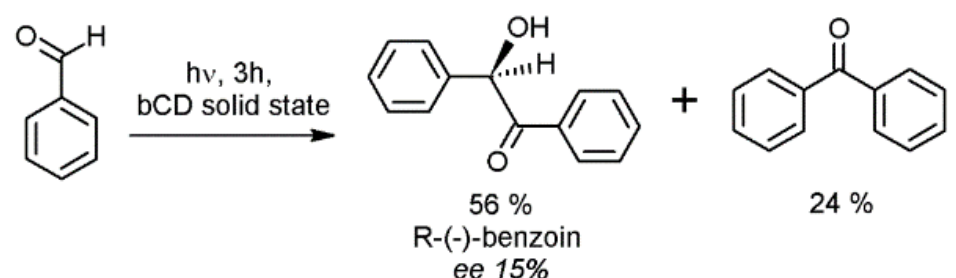

Scheme 15. Photolysis of benzaldehyde with the formation of optically-active benzoin, adapted from [62].

According to Trotta et al. [63], obtaining atropisomers of binaphthyl derivatives out of 2-naphtol 6-bromo-2-naphthol and 2-naphthylamine was possible by oxidative dimerization by $\mathrm{H}_{2} \mathrm{O}_{2}$ in the presence of $\alpha$-, $\beta$ - and $\gamma$-CDs, as well as methyl- $\beta$-cyclodextrin (Me- $\beta-C D)$, heptakis-2,3,6-O-trihydroxyethyl- $\beta$-CD (THE- $\beta$-CD) and heptakis-2,3,6-O-tri-2-hydroxypropyl- $\beta$-CD (THP- $\beta-C D)$ (Scheme 16). Binaphthyl derivatives were obtained with excellent yields up to $93 \%-95 \%$ and fairly good enantiomeric excess around $41 \%-43 \%$, mainly in the presence of modified cyclodextrins: Me- $\beta-C D$, THE- $\beta-C D$ and THP- $\beta-C D$.

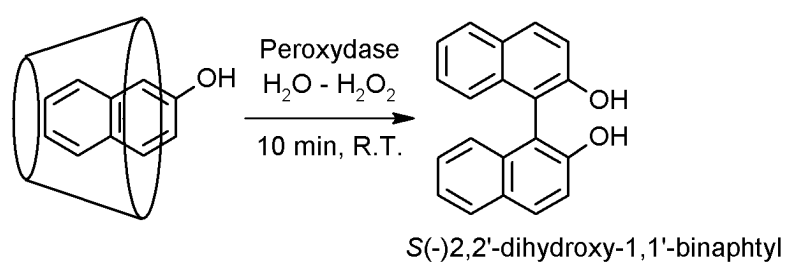

Scheme 16. Enantioselective dimerization of naphthyl derivatives, adapted from [63].

In addition, this group described [63] their attempts of naproxen's $(S)-(-)$-enantiomer obtaining via its ester hydrolysis catalyzed by esterase in the presence of $0 \%, 2.5 \%$ or $5 \%$ Me- $\beta$-CD. Remarkably, the hydrolysis reaction did not take place without methyl- $\beta$-cyclodextrin, while enantiomeric excess was higher at $2.5 \%$ of Me- $\beta-\mathrm{CD}$, reaching $46 \%$. 


\subsection{Cyclodextrins Promoting Asymmetric and Stereospecific Catalysis in Water}

Due to their structure, cyclodextrins can mimic enzymes via the creation of a hydrophobic pocket in water that can concentrate the organocatalysts and reactants, assemble substrates, diminish contacts between bulk water and the reaction transition states and, thus, alter the reaction mechanism and stereochemistry [64]. For example, Huang et al. [64] developed an asymmetric catalytic system for aldol reactions in water mediated by sulfated $\beta-\mathrm{CD}$ (Figure 3). The latter can bind organocatalyst, tert-butylphenoxyproline and associated hydrophobic reactants. This system demonstrates up to $99 \%$ enantioselectivity and $>99 \%$ diastereoselectivity and near quantitative yields for stoichiometric direct aldol reactions of cyclohexanone and aryl aldehydes. It has been observed by the authors that in the water medium, both the enantio- and diastereoselectivities increased greatly, thus indicating that water participated in the reaction transition states through hydrogen bonding and enhanced the stereoselectivity of the reaction.

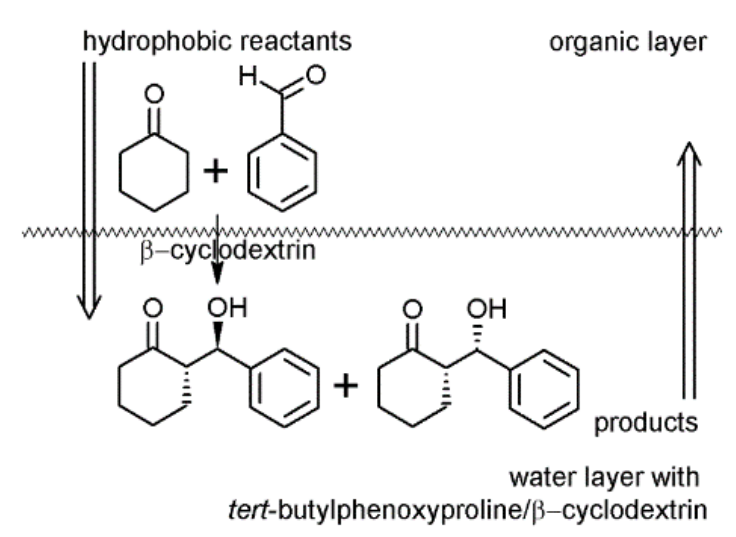

Figure 3. The asymmetric catalytic system in water mediated by hydrosoluble $\beta$-cyclodextrins, adapted from [64].

In another approach, Doyaguez et al. [65] have reported the synthesis of a linear copolymer bearing both pendant proline and permethylated $\beta$-CD groups (Scheme 17). The polymer is water-soluble and, therefore, can catalyze aldol reactions in water medium. The copolymeric catalyst showed a $\mathrm{pH}$-dependent behavior, representing extended single chains with a negative charge at $\mathrm{pH} 7$, catalyzing the reaction in a fast and non-stereoselective mode, and at the isoelectric point ( $\mathrm{pH} 3.8$ ), the copolymer forms multichain hydrophobic nanoaggregates, in which the positive and negative charges of the zwitterionic proline are cancelled by forming charged complexes, most probably stabilized by the permethylated $\beta-C D$. Although the reaction inside such "nanoreactors" runs at a slower rate, it exhibits high stereoselectivity [65].

An asymmetric reduction of hydrophobic ketones by carbonyl reductase in cyclodextrin-containing media has been reported by Zelinski et al. [66,67]. The products, (S)-1-(2-napthyl)-ethanol, $(S)-(E)-4$-phenyl-3-en-2-ol and 1,2,3,4-tetrahydro-2-(1-hydroxyethyl)-1-oxonaphthalene are formed in good yields and high enantiomeric excesses. It has been demonstrated that heptakis-(2,6-di- $O$-methyl)$\beta$-cyclodextrin present in the reaction media at a concentration of $100 \mathrm{mM}$ formed complexes with the ketones and, thus, contributed to higher yields and ee, as well as stabilized the enzyme. 
A good review of the application of cyclodextrins as nanoreactors in various organic reactions has been composed by Zhao and Zhong [68].

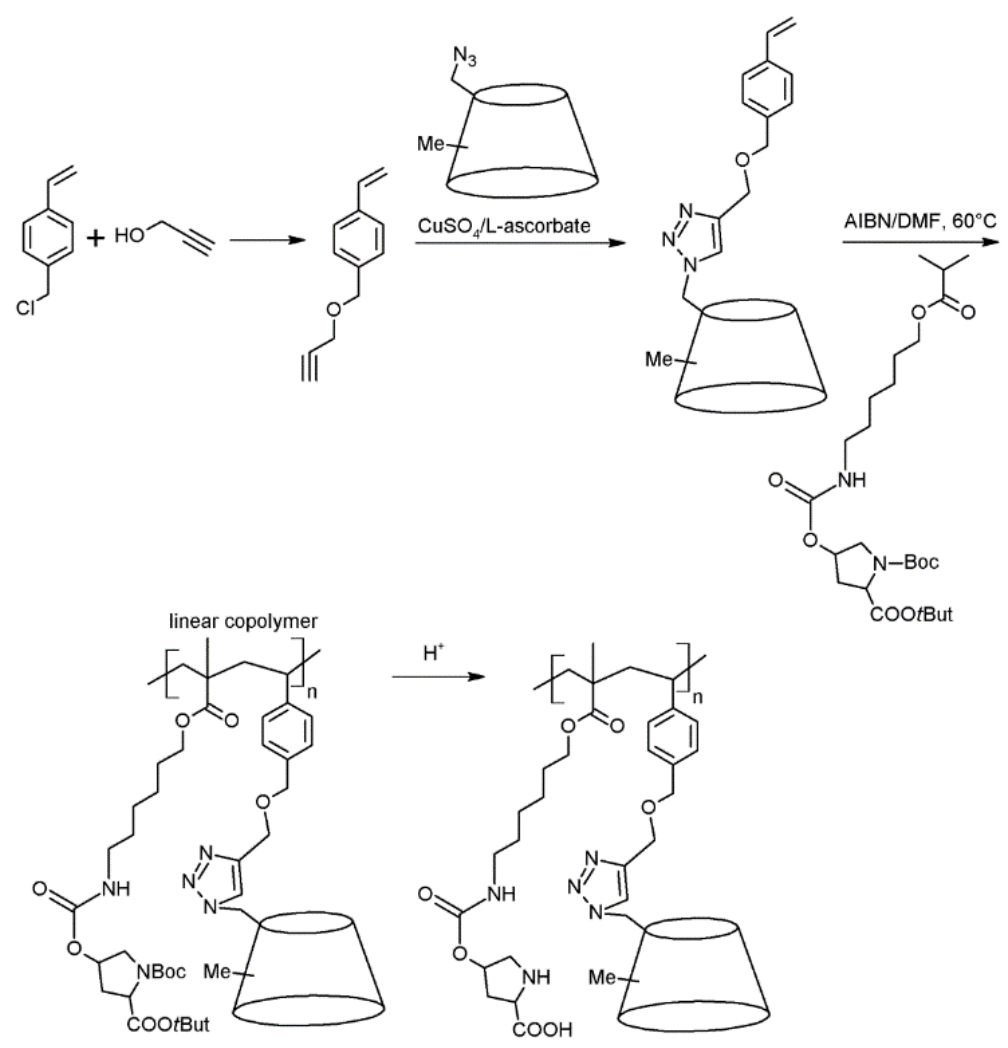

Scheme 17. Synthesis of cyclodextrin-based pH-depended catalytic nanoreactors, adapted from [65].

\section{Conclusions}

Cyclodextrins and their derivatives can be a feasible alternative to traditional catalysts in a variety of reactions. Particularly, cyclodextrins can play the role of nanoreactors in which the asymmetric or stereospecific synthesis is facilitated. In addition, as a part of the metal-containing catalytic system, cyclodextrins can participate in the catalytic process via preorganization of the substrates in the hydrophobic cavity and specific exposure of the reaction affected groups to the metal-catalytic part of the complex. Moreover, a wide range of stereospecific and asymmetric reactions can be performed with the application of non-metallic derivatives of cyclodextrins as catalysts. These include reactions of halogenation and hydrohalogenation, oxidation, reduction, hydrogenation, aldol reactions, photolysis, addition and substitution reactions.

The enantioselectivity of these reactions has been demonstrated to depend on different factors: correlation between the substrate molecular dimensions and the cyclodextrin cavity size, geometry in the approach of the substrate to the "active site", influence of $\mathrm{pH}$ and temperature.

Even though not all enantioselective and stereospecific reactions catalyzed by cyclodextrins known up to now reach high yields and enantioselectivity, there are some evident advantages, like the catalysts' reusability and environmental friendliness, which make them an interesting object for further research and development of new entities with enhanced catalytic properties. 


\section{Acknowledgments}

The authors are grateful for the funding of this research under the Moldovan State Program Project 14.518.04.08A.

\section{Author Contributions}

Fliur Macaev and Veaceslav Boldescu have equally contributed to the analysis of the data and the development of this paper.

\section{Conflicts of Interest}

The authors declare no conflict of interest.

\section{References}

1. Hapiot, F.; Ponchel, A.; Tilloy, S.; Monflier, E. Cyclodextrins and their applications in aqueous-phase metal-catalyzed reactions. C. R. Chim. 2011, 14, 149-166.

2. Takahashi, K. Organic reactions mediated by cyclodextrins. Chem. Rev. 1998, 98, 2013-2034.

3. Breslow, R.; Dong, S.D. Biomimetic reactions catalyzed by cyclodextrins and their derivatives. Chem. Rev. 1998, 98, 1997-2012.

4. Noël, S.; Léger, B.; Ponchel, A.; Philippot, K.; Denicourt-Nowicki, A.; Roucoux, A.; Monflier, E. Cyclodextrin-based systems for the stabilization of metallic (0) nanoparticles and their versatile applications in catalysis. Catal. Today 2014, 235, 20-32.

5. Hapiot, F.; Bricout, H.; Menuel, S.; Tilloy, S.; Monflier, E. Recent breakthroughs in aqueous cyclodextrin-assisted supramolecular catalysis. Catal. Sci. Technol. 2014, 4, 1899-1908.

6. Fillet, M.; Hubert, P.; Crommen, J. Enantiomeric separations of drugs using mixtures of charged and neutral cyclodextrins. J. Chromatogr. A. 2000, 875, 123-134.

7. Bicchi, C.; D'Amato, A.; Rubiolo, P. Cyclodextrin derivatives as chiral selectors for direct gas chromatographic separation of enantiomers in the essential oil, aroma and flavour fields. $J$. Chromatogr. A 1999, 843, 99-121.

8. Xiao, Y.; Ng, S.C.; Tan, T.T.Y.; Wang, Y. Recent development of cyclodextrin chiral stationary phases and their applications in chromatography. J. Chromatogr. A. 2012, 1269, 52-68.

9. Tang, W.; Ng, S.C.; Sun, D. Modified Cyclodextrins for Chiral Separation; Springer: New York, NY, USA, 2013.

10. Schlatter, A.; Kundu, M.K.; Woggon, W.D. Enantioselective reduction of aromatic and aliphatic ketones catalysed by ruthenium complexes attached to $\beta$-cyclodextrin. Angew. Chem. 2004, 116, 6899-6902.

11. Shen, H.M.; Ji, H.B. Cyclodextrin- $\left[\mathrm{RuCl}_{2} \text { (Arene) }\right]_{2}$ conjugates: Another way to enhance the enantioselectivity of aromatic ketones reduction by aromatic ligands' volume. Tetrahedron 2013, 69, 8360-8367.

12. Sakuraba, H.; Maekawa, H. Enantioselective oxidation of sulfides catalyzed by chiral Mo $\mathrm{V}$ and $\mathrm{Cu}$ II complexes of catechol-appended $\beta$-cyclodextrin derivatives in water. J. Incl. Phenom. Macrocycl. Chem. 2006, 54, 41-45. 
13. Wong, Y.T.; Yang, C.; Ying, K.C.; Jia, G. Synthesis of a novel $\beta$-cyclodextrin-functionalized diphosphine ligand and its catalytic properties for asymmetric hydrogenation. Organometallics 2002, 21, 1782-1787.

14. Jouffroy, M.; Sémeril, D.; Armspach, D.; Matt, D. Phosphane-phosphite chelators built on a $\alpha$-cyclodextrin scaffold: Application in Rh-catalysed asymmetric hydrogenation and hydroformylation. Eur. J. Org. Chem. 2013, 2013, 6069-6077.

15. Yang, J.; Gabriele, B.; Belvedere, S.; Huang, Y.; Breslow, R. Catalytic oxidations of steroid substrates by artificial cytochrome P-450 enzymes. J. Org. Chem. 2002, 67, 5057-5067.

16. Engeldinger, É.; Armspach, D.; Matt, D.; Toupet, L.; Wesolek, M. Synthesis of large chelate rings with diphosphites built on a cyclodextrin scaffold. Unexpected formation of 1, 2-phenylene-capped a-cyclodextrins. C. R. Chim. 2002, 5, 359-372.

17. Cassez, A.; Kania, N.; Hapiot, F.; Fourmentin, S.; Monflier, E.; Ponchel, A. Chemically modified cyclodextrins adsorbed on $\mathrm{Pd} / \mathrm{C}$ particles: New opportunities to generate highly chemo- and stereoselective catalysts for Heck reaction. Catal. Commun. 2008, 9, 1346-1351.

18. Senra, J.D.; Malta, L.F.B.; Souza, A.L.F.; Aguiar, L.; Antunes, O.A.C. Palladium on calcium carbonate combined to 2-hydroxypropyl- $\alpha / \beta$-cyclodextrins: A selective catalytic system for aqueous heck coupling and hydroarylation. Adv. Synth. Catal. 2008, 350, 2551-2558.

19. Shen, H.M.; Ji, H.B. Biomimetic asymmetric aldol reactions catalyzed by proline derivatives attached to $\beta$-cyclodextrin in water. Tetrahedron Lett. 2012, 53, 3541-3545.

20. Jouffroy, M.; Gramage-Doria, R.; Sémeril, D.; Armspach, D.; Matt, D.; Oberhauser, W.; Toupet, L. Phosphinocyclodextrins as confining units for catalytic metal centres. Applications to carbon-carbon bond forming reactions. Beilstein J. Org. Chem. 2014, 10, 2388-2405.

21. Jouffroy, M.; Gramage-Doria, R.; Armspach, D.; Sémeril, D.; Oberhauser, W.; Matt, D.; Toupet, L. Confining phosphanes derived from cyclodextrins for efficient regio- and enantioselective hydroformylation. Angew. Chem. Int. Ed. 2014, 53, 3937-3940.

22. Tanaka, Y.; Sakuraba, H.; Nakanishi, H. Asymmetric halogenation and hydrohalogenation of olefins in crystalline cyclodextrin complexes. J. Chem. Soc. Chem. Commun. 1983, 17, 947-948.

23. Tanaka, Y.; Sakuraba, H.; Oka, Y.; Nakanishi, H. Asymmetric halogenation and hydrohalogenation of ethyl trans-cinnamate in crystalline cyclodextrin complexes. J. Incl. Phenom. 1984, 2, 841-850.

24. Sakuraba, H.; Nakai, T.; Tanaka, Y. Asymmetric halogenation and hydrohalogenation of trans-cinnamic acid in crystalline cyclodextrin complexes. J. Incl. Phenom. 1984, 2, 829-839.

25. Sakuraba, H.; Ishizaki, H.; Tanaka, Y.; Shimizu, T. Asymmetric halogenation and hydrohalogenation of styrene in crystalline cyclodextrin complexes. J. Incl. Phenom. 1987, 5, 449-458.

26. Tanaka, Y.; Sakuraba, H.; Nakanishi, H. Asymmetric halogenation and hydrohalogenation of trans-2-butenoic acid in a crystalline $\alpha$-cyclodextrin complex. J. Org. Chem. 1990, 55, 564-567.

27. Pitchumani, K.; Velusamy, P.; Sabithamala, S.; Srinivasan, C. Modification of chemical reactivity upon cyclodextrin encapsulation: Asymmetric bromination of chalcone and benzylideneacetone. Tetrahedron 1994, 50, 7903-7912.

28. Kanagaraj, K.; Pitchumani, K. Per-6-amino- $\beta$-cyclodextrin as a chiral base catalyst promoting one-pot asymmetric synthesis of 2-aryl-2,3-dihydro-4-quinolones. J. Org. Chem. 2012, 78, 744-751.

29. Kanagaraj, K.; Suresh, P.; Pitchumani, K. Per-6-amino- $\beta$-cyclodextrin as a reusable promoter and chiral host for enantioselective Henry reaction. Org. Lett. 2010, 12, 4070-4073. 
30. Suresh, P.; Pitchumani, K. Per-6-amino- $\beta$-cyclodextrin catalysed asymmetric Michael addition of nitromethane and thiols to chalcones in water. Tetrahedron Asymmetry 2008, 19, 2037-2044.

31. Baba, N.; Matsumura, Y.; Sugimoto, T. Asymmetric reduction of aryl trifluoromethyl ketones with an achiral NADH model compound in a chiral hydrophobic binding site of sodiumcholate micelle, $\beta$-cyclodextrin and bovine serum albumin. Tetrahedron Lett. 1978, 19, 4281-4284.

32. Fornasier, R.; Reniero, F.; Scrimin, P.; Tonellato, U. Asymmetric reductions by sodium borhydride of ketone- $\beta$-cyclodextrin complexes. J. Org. Chem. 1985, 50, 3209-3211.

33. Sakuraba, H.; Inomata, N.; Tanaka, Y. Asymmetric reduction of ketones with crystalline cyclodextrin complexes of amine-boranes. J. Org. Chem. 1989, 54, 3482-3484.

34. Kawajiri, Y.; Motohashi, N. Strong asymmetric induction without covalent bond connection. J. Chem. Soc. Chem. Commun. 1989, 1336-1337.

35. Hattori, K.; Takahashi, K.; Uematsu, M.; Sakai, N. Multiple interactions between host cyclodextrin and guest compound assisting asymmetrically selective reduction with $\mathrm{NaBH}_{4}$ in aqueous media. Chem. Lett. 1990, 8, 1463-1466.

36. Hattori, K.; Takahashi, K.; Sakai, N. Enantioface differentiating reduction of keto acid in the presence of 6-deoxy-6-amino- $\beta$-cyclodextrin with $\mathrm{NaBH}_{4}$ in aqueous media. Bull. Chem. Soc. Jpn. 1992, 65, 2690-2696.

37. Takahashi, K.; Yokomizo, H.; Ishiyama, K.; Kitsuta, M.; Ohashi, M. New aspects of cyclodextrin chemistry induced by outside complex formation; asymmetric reduction of indol-3-pyruvic acid with $\mathrm{NaBH}_{4}$ in aqueous solution. J. Incl. Phenom. Macrocycl. Chem. 2006, 56, 95-99.

38. Tang, W.; Tang, J.; Ng, S.C.; Chan, H.S.O. Asymmetric reduction of acetophenones with $\mathrm{NaBH}_{4}$ in the presence of mono-6-(1-methyl-3-imidazolium)-6-deoxy- $\beta$-cyclodextrin tosylate. $J$. Incl. Phenom. Macrocycl. Chem. 2006, 56, 287-290.

39. Wan, Y.; Wang, X.; Liu, N. Interaction of $\beta$-cyclodextrin as catalyst with acetophenone in asymmetric reaction: A theoretical survey. J. Mol. Model. 2014, 20, 1-7.

40. Reddy, M.A.; Bhanumathi, N.; Rao, K.R. Asymmetric synthesis of 2-azido-1-arylethanols from azido aryl ketone-beta-cyclodextrin complexes and sodium borohydride in water. Chem. Commun. Camb. 2001, 19, 1974-1975.

41. Ravichandran, R. Stereoselective hydrogenation of $(2 S, 5 R)-(-)$-menthone in presence of $\beta$-cyclodextrin. J. Mol. Catal. A Chem. 2006, 256, 216-218.

42. Drabowicz, J.; Mikołajczyk, M. Asymmetric oxidation of sulfides to sulfoxides catalyzed by $\beta$-cyclodextrin. Phosphorus Sulfur Relat. Elem. 1984, 21, 245-248.

43. Czarnik, A.W. Cyclodextrin-mediated chiral sulfoxidations. J. Org. Chem. 1984, 49, 924-927.

44. Rao, K.R.; Sattur, P.B. Asymmetric synthesis of $\alpha, \alpha$-dichlorosulphoxides from substituted thioacetates and sodium hypochlorite in $\beta$-cyclodextrin complexes. J. Chem. Soc. Chem. Commun. 1989, 342-343.

45. Sakuraba, H.; Natori, K.; Tanaka, Y. Asymmetric oxidation of alkyl aryl sulfides in crystalline cyclodextrin complexes. J. Org. Chem. 1991, 56, 4124-4129.

46. Fornasier, R.; Scrimin, P.; Tecilla, P.; Tonellato, U. Asymmetric oxidation of sulfides in the presence of cyclodextrins: Effect of the precomplexation of the reactants. Phosphorus Sulfur Relat. Elem. 1988, 35, 211-213. 
47. Deary, M.E.; Davies, D.M. Evidence for cyclodextrin dioxiranes. Part 2. Catalytic and enantioselective properties of cyclodextrin dioxiranes formed from keto-derivatised hydroxypropyl-cyclodextrins. Carbohydr. Res. 1999, 317, 10-18.

48. Mojr, V.; Herzig, V.; Buděšínský, M.; Cibulka, R.; Kraus, T. Flavin-cyclodextrin conjugates as catalysts of enantioselective sulfoxidations with hydrogen peroxide in aqueous media. Chem. Commun. 2010, 46, 7599-7601.

49. Mojr, V.; Buděšínský, M.; Cibulka, R.; Kraus, T. Alloxazine-cyclodextrin conjugates for organocatalytic enantioselective sulfoxidations. Org. Biomol. Chem. 2011, 9, 7318-7326.

50. Hartman, T.; Herzig, V.; Buděšínský, M.; Jindřich, J.; Cibulka, R.; Kraus, T. Flavin-cyclodextrin conjugates: Effect of the structure on the catalytic activity in enantioselective sulfoxidations. Tetrahedron Asymmetry 2012, 23, 1571-1583.

51. Colonna, S.; Manfredi, A.; Annunziata, R.; Gaggero, N.; Casella, L. Biomimetic asymmetric synthesis. Enantioselective Weitz-Scheffer epoxidation of vitamin K3 and analogs in the presence of cyclodextrins. J. Org. Chem. 1990, 55, 5862-5866.

52. Chan, W.K.; Yu, W.Y.; Che, C.M.; Wong, M.K. A cyclodextrin-modified ketoester for stereoselective epoxidation of alkenes. J. Org. Chem. 2003, 68, 6576-6582.

53. Rousseau, C.; Christensen, B.; Petersen, T.E.; Bols, M. Cyclodextrins containing an acetone bridge. Synthesis and study as epoxidation catalysts. Org. Biomol. Chem. 2004, 2, 3476-3482.

54. Rousseau, C.; Christensen, B.; Bols, M. Artificial epoxidase II. Synthesis of cyclodextrin ketoesters and epoxidation of alkenes. Eur. J. Org. Chem. 2005, 13, 2734-2739.

55. Shen, Z.; Ma, J.; Liu, Y.; Jiao, C.; Li, M.; Zhang, Y. $\beta$-cyclodextrin-immobilized (4S)-phenoxy(S)-proline as a catalyst for direct asymmetric aldol reactions. Chirality 2005, 17, 556-558.

56. Shen, H.M.; Ji, H.B. Amino alcohol-modified $\beta$-cyclodextrin inducing biomimetic asymmetric oxidation of thioanisole in water. Carbohydr. Res. 2012, 354, 49-58.

57. Liu, K.; Zhang, G. Direct asymmetric aldol reactions in aqueous media catalyzed by a $\beta$-cyclodextrin-proline conjugate with a urea linker. Tetrahedron Lett. 2015, 56, 243-246.

58. Bonetto, L.; Fornasier, R.; Tonellato, U. Enantioselective addition of diethylzinc to aldehydes promoted by alkylated-cyclodextrin derivatives. Gazz. Chim. Ital. 1995, 125, 63-63.

59. Fornasier, R.; Marcuzzi, F.; Piva, M.; Tonellato, U. Enantioselective allylation and tert-butylation of 2-cyclohexanone in aqueous media in the presence of $\beta$-cyclodextrins as chiral auxiliaries. Gazz. Chim. Ital. 1996, 126, 633-634.

60. Reddy, L.R.; Bhanumathi, N.; Rama Rao, K. Dynamic kinetic asymmetric synthesis of $\beta$-aminoalcohols from racemic epoxides in cyclodextrin complexes under solid state conditions. Chem. Commun. 2000, 23, 2321-2322.

61. Asahara, H.; Kida, T.; Iwamoto, T.; Hinoue, T.; Akashi, M. Kinetic resolution of primary amines via enantioselective $\mathrm{N}$-acylation with acyl chlorides in the presence of supramolecular cyclodextrin nanocapsules. Tetrahedron 2014, 70, 197-203.

62. Rao, V.P.; Turro, N.J. Asymmetric induction in benzoin by photolysis of benzaldehyde adsorbed in cyclodextrin cavities. Tetrahedron Lett. 1989, 30, 4641-4644.

63. Trotta, F.; Cravotto, G.; Rossignoli, S. Asymmetric synthesis in the presence of cyclodextrins. J. Incl. Phenom. Macrocycl. Chem. 2002, 44, 293-296. 
64. Huang, J.; Zhang, X.; Armstrong, D.W. Highly efficient asymmetric direct stoichiometric aldol reactions on/in water. Angew. Chem. Int. Ed. 2007, 46, 9073-9077.

65. Doyaguez, E.G.; Rodríguez-Hernández, J.; Corrales, G.; Fernández-Mayoralas, A.; Gallardo, A. Water-soluble pendant copolymers bearing proline and permethylated $\beta$-cyclodextrin: pH-dependent catalytic nanoreactors. Macromolecules 2012, 45, 7676-7683.

66. Zelinski, T.; Kula, M.R. Asymmetric enzymatic reduction of lipophilic ketones in aqueous solution containing cyclodextrins. Biocatal. Biotransform. 1997, 15, 57-74.

67. Zelinski, T.; Liese, A.; Wandrey, C.; Kula, M.R. Asymmetric reductions in aqueous media: Enzymatic synthesis in cyclodextrin containing buffers. Tetrahedron Asymmetry 1999, 10, 1681-1687.

68. Zhao, W.; Zhong, Q. Recent advance of cyclodextrins as nanoreactors in various organic reactions: A brief overview. J. Incl. Phenom. Macrocycl. Chem. 2012, 72, 1-14.

(C) 2015 by the authors; licensee MDPI, Basel, Switzerland. This article is an open access article distributed under the terms and conditions of the Creative Commons Attribution license (http://creativecommons.org/licenses/by/4.0/). 